\title{
Numerical investigation of convective cooling in minimizing skin burns during radiofrequency ablation of breast tumor
}

\author{
SUNDEEP SINGH and RAMJEE REPAKA*(D) \\ Department of Mechanical Engineering, Indian Institute of Technology Ropar, Rupnagar 140001, India \\ e-mail: ramjee.repaka@gmail.com
}

MS received 20 April 2017; revised 27 February 2018; accepted 22 March 2018; published online 1 June 2018

\begin{abstract}
Skin burns is one of the most common complications reported during treatment of early-stage breast cancer with radiofrequency ablation (RFA) technique. In this regard, the present study aims to analyze the efficacy of forced convection surface cooling in minimizing the skin burns during RFA of breast tumor. The study considers a heterogeneous three-dimensional numerical model of breast that has been constructed based on the anatomical details available in the literature. A spherical tumor of $1.5 \mathrm{~cm}$ has been embedded in the numerical model of breast to represent in-situ tumor in its early stage. A programmable temperature-controlled RFA has been performed by incorporating the closed-loop feedback PID controller into the numerical model. The thermo-electric analysis has been performed using a finite element based commercial solver COMSOL Multiphysics ${ }^{\circledR}$ to obtain the temperature distribution by incorporating the coupled electric field distribution, Pennes bioheat equation and Arrhenius rate equation. The temperature dependent electrical and thermal conductivities of both the tissue and tumor along with damage dependent perfusion rate have been incorporated to achieve better correlation with the clinical RFA. The numerical simulation results revealed that, there is a significant reduction in the temperature at outer periphery of breast with increase in convective heat transfer coefficient. Further, the effects of variation in surface cooling on temperature distribution, input voltage requirement and treatment time required for complete tumor necrosis have been studied. The simultaneous application of forced convective surface cooling along with RFA could play a vital role in addressing the most common complication of skin burns during treatment of breast cancer.
\end{abstract}

Keywords. Radiofrequency ablation; breast cancer; skin burns; convective cooling; bioheat transfer; finite element method.

\section{Introduction}

Globally, breast cancer is the second most diagnosed type of cancer after lung cancer (11.9\% of all cancer incidences) and the fifth most common cause of cancer death $(6.4 \%$ of all cancer deaths) [1]. According to WHO, there were $1,44,937$ new breast cancer cases diagnosed in India in 2012 , with the mortality rate of 70,218 [1]. The rapid rise of breast cancer cases among women in India is so alarming that for the first time, it has crossed the cervical cancer that ruled the top most position for almost four decades, in terms of incidences as well as deaths [1,2]. The detection of breast cancer at the earliest due to breast cancer awareness programs, wide use of screening mammography and advances in modern imaging modalities has resulted in evolution of breast cancer treatment from radical mastectomy to breast-conserving surgery. Although, breast conserving surgery remains the gold standard for treatment of localized breast cancer but is associated with morbidity in

*For correspondence particular high re-excision rates and poor cosmetic outcomes [3, 4]. To overcome this deficiency, non-surgical minimally invasive thermal ablative techniques have been explored in clinical practices with the intention of achieving equivalent efficacy with improved cosmesis. The potential advantages of non-surgical treatment of breast cancer are reduction in treatment cost, reduction in morbidity and mortality rates, shorter recovery time and improved quality of life of the cancer patients [5].

Several non-surgical minimally invasive ablative techniques are available that may either cool or heat tumors sufficiently to induce irreversible cell injury, viz., radiofrequency ablation (RFA), laser ablation (LA), microwave ablation (MWA), cryoablation, and high-intensity focused ultrasound (HIFU) ablation [6]. Among these different techniques, radiofrequency ablation (RFA) is the most extensively studied technique that has already emerged as an alternative treatment modality in treatment of liver cancer. RFA is a novel technique that utilizes the direct placement of one or more radiofrequency electrodes into the tumor tissue by using percutaneous image guidance 
system to destroy the tumor. Once positioned, high frequency alternating current $(450-550 \mathrm{kHz})$ is delivered through the probe into the tissue, which induces frictional (resistive) heating when the ions in the tissue attempt to follow the changing directions of the alternating current. This frictional heating causes destruction of tumor cell by instantaneous induction of protein coagulation that irreversibly damages key cytosolic and mitochondrial enzymes and nucleic acid histone complexes [7].

The application of RFA in treatment of breast cancer is still a developing area of research even though breast as an organ seems to be an ideal model for RFA because of its superficial location on the thorax and the absence of any intervening organs [5]. However, skin burn is one of the major complication, since the first clinical study of RFA on human breast cancer was reported in year 1999 by Jeffrey et al [8]. To address the issue, Oura et al [9] subcutaneously injected $5 \%$ glucose, in addition to applying ice packs to cool the skin just above the tumor to prevent skin burns during RFA of breast cancer. The injection of $5 \%$ glucose resulted in enlargement of the distance between the tumor and the skin, as well as interrupting the radiofrequency energy to the affected skin due to very high impedance

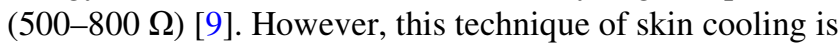
very much dependent on the image guided modalities and radiologist's experience to precisely inject $5 \%$ glucose just above the tumor. In this regard, the present study proposes and evaluates the efficacy of forced convection cooling in minimizing the skin burns during RFA application of breast tumor.

\section{Model and formulation}

\subsection{Problem definition}

In the present study a heterogeneous three-dimensional model of breast has been considered in which a spherical tumor of $1.5 \mathrm{~cm}$ diameter has been embedded to represent in-situ tumor in its early stage as shown in figure 1. In accordance to the BI-RADS (Breast Imaging Reporting and Data System), the breast density levels for women can be classified into four major categories, viz., extremely dense, heterogeneously dense, scattered fibroglandular and predominantly fatty, having fat layer thickness of $2.5 \mathrm{~mm}$, $5.5 \mathrm{~mm}, 11.1 \mathrm{~mm}$ and $23.9 \mathrm{~mm}$, respectively [10]. The numerical study considers the extremely dense breast model having lower fatty tissue thickness $(2.5 \mathrm{~mm})$ where the location of tumor is kept close to the skin surface so as to model the worst possible scenario of RFA of breast cancer. Due to prevailing lower thermal and electrical conductivities, the increase in the subcutaneous fat layer thickness, from extremely dense to predominantly fatty breast, by itself will result in some reduction of temperature at the outer periphery of the breast. A monopolar electrode has been inserted in the breast tumor such that the active

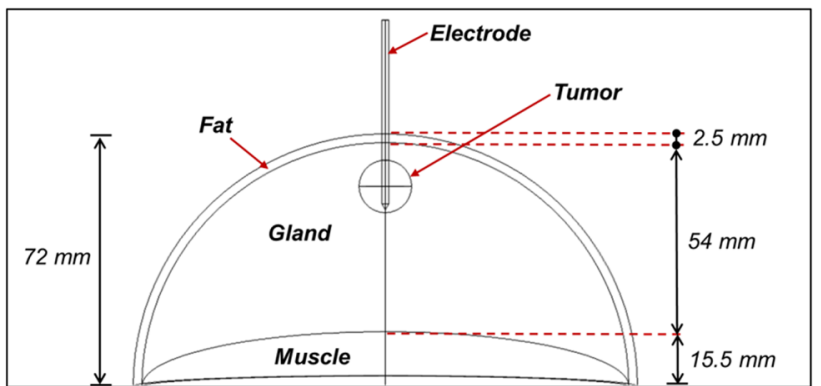

(a)

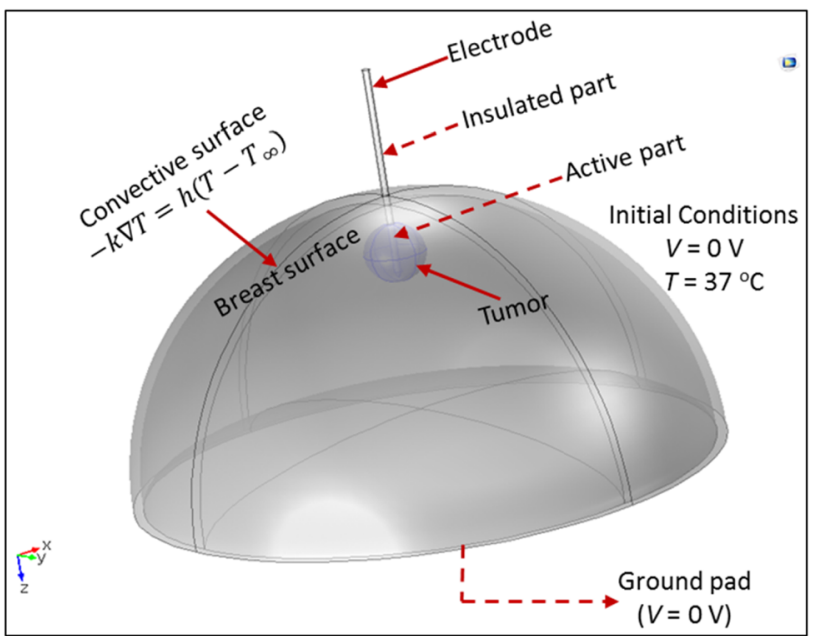

(b)

Figure 1. (a) Schematic of cross-sectional view of the heterogeneous breast model and (b) three-dimensional computational domain of breast model in COMSOL Multiphysics ${ }^{\circledR}$.

part is completely encapsulated within the tumor. A temperature-controlled RFA has been performed for 20 minutes at a target temperature of $95^{\circ} \mathrm{C}$ by incorporating PID (proportional-derivative-integral) controller at the active tip of electrode to mitigate any adverse effects of tissue carbonization and charring. The initial voltage of the breast model before the onset of RFA has been considered to be zero. The electrical boundary condition for the bottom surface of the breast has been assumed to be zero (simulating a ground pad). Further, the initial temperature of breast model has been considered to be same as that of the core body temperature of the human body, $T_{b}\left(=37^{\circ} \mathrm{C}\right)$ and the initial temperature of the electrode has been set to $25{ }^{\circ} \mathrm{C}$, simulating the ambient room temperature conditions. The electrical and thermal boundary conditions at the interfaces between tumor and gland, electrode and tumor, electrode and gland, electrode and fat, tumor and gland, gland and fat, and gland and muscle have been considered to be continuous. The breast skin surface is exposed to ambience and is at the convective cooling condition $\left(-k \nabla T=h\left(T-T_{\infty}\right)\right)$ where $h$ is convective heat transfer coefficient $\left(\mathrm{W} / \mathrm{m}^{2} \mathrm{~K}\right)$ and $T_{\infty}$ is the surrounding ambient temperature considered to be $25{ }^{\circ} \mathrm{C}$. Further, the different values of $h$ considered for convective cooling in the present 
Table 1. Electrical and thermo-physical properties of different materials used in RFA modelling (460 kHz).

\begin{tabular}{|c|c|c|c|c|c|c|}
\hline $\begin{array}{l}\text { Material } \\
\text { (Tissue/ } \\
\text { Electrode) }\end{array}$ & $\begin{array}{c}\text { Electrical } \\
\text { conductivity } \sigma(\mathrm{S} / \\
\mathrm{m})\end{array}$ & $\begin{array}{c}\text { Specific heat } \\
\text { capacity } c(\mathrm{~J} / \mathrm{kg} \mathrm{K})\end{array}$ & $\begin{array}{c}\text { Thermal } \\
\text { conductivity } k(\mathrm{~W} / \\
\mathrm{m} \mathrm{K})\end{array}$ & $\begin{array}{l}\text { Density } \rho \\
\left(\mathrm{kg} / \mathrm{m}^{3}\right)\end{array}$ & $\begin{array}{c}\text { Metabolic heat } \\
\text { generation } Q_{m}\left(\mathrm{~W} / \mathrm{m}^{3}\right)\end{array}$ & $\begin{array}{c}\text { Blood } \\
\text { perfusion } \omega_{b} \\
\left(\mathrm{~s}^{-1}\right)\end{array}$ \\
\hline Gland & 0.563 & 2960 & 0.33 & 1041 & 700 & $0.5 \times 10^{-3}$ \\
\hline Fat & 0.0254 & 2348 & 0.21 & 911 & 400 & $0.2 \times 10^{-3}$ \\
\hline Muscle & 0.439 & 3421 & 0.49 & 1090 & 700 & $0.8 \times 10^{-3}$ \\
\hline Tumor & 0.71 & 3770 & 0.48 & 1050 & 13600 & $5.3 \times 10^{-3}$ \\
\hline Electrode & $10^{8}$ & 840 & 18 & 6450 & - & - \\
\hline Trocar Base & $10^{-5}$ & 1045 & 0.026 & 70 & - & - \\
\hline Trocar Tip & $4 \times 10^{6}$ & 132 & 71 & 7900 & - & - \\
\hline
\end{tabular}

study are 100, 200, 300, 400 and $800 \mathrm{~W} / \mathrm{m}^{2} \mathrm{~K}$. Such high values of convective heat transfer coefficient are feasible by using mild cryogen sprays [11, 12]. Further, the material properties used in present numerical study have been presented in table $1[10,13,14]$.

\subsection{Mathematical modelling of temperature- controlled RFA}

A quasi-static approach is used to solve the electro-thermal problem and determine the heat deposition due to RF energy since in the frequency range of RFA displacement current is negligibly small as compared to the resistive current. Thus, the electric potential is computed using generalized Laplace equation

$$
\nabla \cdot \sigma(T) \nabla V=0
$$

where $\sigma$ is the electrical conductivity $(\mathrm{S} / \mathrm{m})$ and $V$ is the electric potential $(\mathrm{V})$. Further, the volumetric heat source due to RF heating $Q_{p}\left(\mathrm{~W} / \mathrm{m}^{3}\right)$ is given by

$$
Q_{p}=\sigma(T)|\nabla V|^{2}
$$

In the present study, Pennes bioheat equation has been used to simulate temperature distribution during RFA of breast cancer [15]

$$
\rho c \frac{\partial T}{\partial t}=\nabla \cdot k(T) \nabla T-\rho_{b} c_{b} \omega_{b}(t)\left[T-T_{b}\right]+Q_{m}+Q_{p}
$$

where $T$ is the temperature in $\mathrm{K}, \rho$ is density in $\mathrm{kg} / \mathrm{m}^{3}, c$ is the specific heat in $\mathrm{J} / \mathrm{kg} / \mathrm{K}, k$ is the thermal conductivity in $\mathrm{W} / \mathrm{m} / \mathrm{K}, \rho_{b}$ is the blood density $\left(1050 \mathrm{~kg} / \mathrm{m}^{3}\right), c_{b}$ is the blood specific heat $(3617 \mathrm{~J} / \mathrm{kg} / \mathrm{K}), \omega_{b}$ is blood perfusion rate $(1 / \mathrm{s}), Q_{m}$ is the volumetric heat generated by metabolism in $\mathrm{W} / \mathrm{m}^{3}, Q_{p}$ is the volumetric heating due to RF power in $\mathrm{W} / \mathrm{m}^{3}$ and is by computed using Eq. (2) and $T_{b}$ is blood temperature $\left(37^{\circ} \mathrm{C}\right)$.

The present study considers linear variation of both electrical and thermal conductivities with temperature and is given by Eq. (4) and Eq. (5), respectively [16]

$$
\begin{gathered}
\sigma(T)=\sigma_{0}\left[1+0.02\left(T-T_{b}\right)\right] \\
k(T)=k_{0}+0.0013\left(T-T_{b}\right)
\end{gathered}
$$

where $\sigma_{\mathrm{o}}$ and $k_{\mathrm{o}}$ are the constant electrical and thermal conductivities, respectively, at core body temperature, $T_{b}$ $=37^{\circ} \mathrm{C}$ presented in table 1 .

Further, earlier studies have reported a strong dependence of perfusion algorithm on the size of ablation volume produced during RFA application [17, 18]. Thus, the present study considers a non-linear piece-wise model of blood perfusion to achieve better correlation with clinical scenario, where the blood perfusion initially increases due to hyperemia and later decreases due to damage to the microvasculature, as given by $[19,20]$

$$
\omega_{b}(t)=\left\{\begin{array}{lll}
\omega_{b, 0} & \text { for } & \Omega(t) \leq 0 \\
\omega_{b, 0}\left[1+25 \Omega(t)-260 \Omega(t)^{2}\right] & \text { for } & 0<\Omega(t) \leq 0.1 \\
\omega_{b, 0} \exp [-\Omega(t)] & \text { for } & \Omega(t)>0.1
\end{array}\right\}
$$

where $\omega_{b, o}$ is the constant blood perfusion given in table 1 and $\Omega(t)$ is the induced thermal damage.

In the present study induced thermal damage $\Omega(t)$ has been computed using well-established first order Arrhenius rate equation, where the relation between the tissue death with the temperature and the treatment time is expressed as [21]

$$
\Omega(t)=\int_{0}^{t} A e^{\frac{-E_{a}}{R T(t)}} d t
$$

where $t$ is the ablation time (s), $A$ is a frequency factor (1.18 $\times 10^{44} \mathrm{~s}^{-1}$ ) [22], $E_{a}$ is an activation energy for irreversible damage reaction $\left(3.02 \times 10^{5} \mathrm{~J} / \mathrm{mol}\right)$ [22] and $R$ is the universal gas constant $(8.314 \mathrm{~J} / \mathrm{mol} / \mathrm{K})$. Further, the damage integral value of $\Omega(\mathrm{t})=1$, which corresponds to $63 \%$ probability of cell death, has been employed as a critical threshold to represent tissue death [21]. All cells within the tissue for $\Omega(\mathrm{t})<1$ have been considered to be alive. 


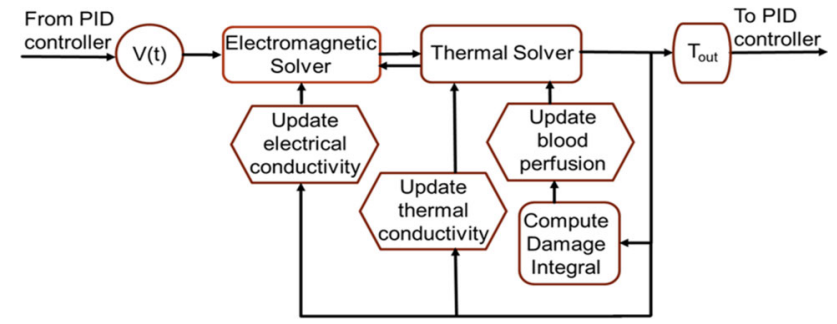

Figure 2. Flow chart representation of data flow used in FEM to compute temperature distribution and ablation volume during temperature-controlled RFA.

The present study models a programmable temperaturecontrolled mode by incorporating a closed-loop feedback proportional-integral-derivative (PID) controller that gauges the input error, i.e., the difference between the set tip temperature and the current tip temperature and accordingly modulates the output (i.e., input voltage) to maintain the pre-set target temperature of $95^{\circ} \mathrm{C}$. The input voltage $\mathrm{V}(t)$, applied on the active part of the electrode during temperature-controlled RFA is given by [23, 24]

$$
V(t)=K_{p} e(t)+K_{i} \int_{0}^{t} e(\tau) d \tau+K_{d} \frac{d}{d t} e(t)
$$

where $V$ is the applied voltage $(\mathrm{V}), e$ is the error, and $K_{p}$ $(0.02), K_{i}(0.01)$ and $K_{d}(0.001)$ are the proportional, integral and derivative gains, respectively [24, 25].

\subsection{Numerical simulation}

The COMSOL Mutiphysics software (COMSOL Inc., AB, Stockholm, Sweden) has been used as a platform to solve the coupled electric-thermal problem of RFA. The complete data flow used in the finite element model implemented in COMSOL Multiphysics software to compute temperature distribution and ablation volume has been depicted in figure 2. The computational domain has been discretized into heterogeneous tetrahedral elements using free meshing generator of $\mathrm{COMSOL}^{\circledR}$ that provides different meshing size parameters based on the maximum element size, minimum element size, maximum element growth rate, curvature factor and resolution of narrow region. Also, by default there are predefined meshing

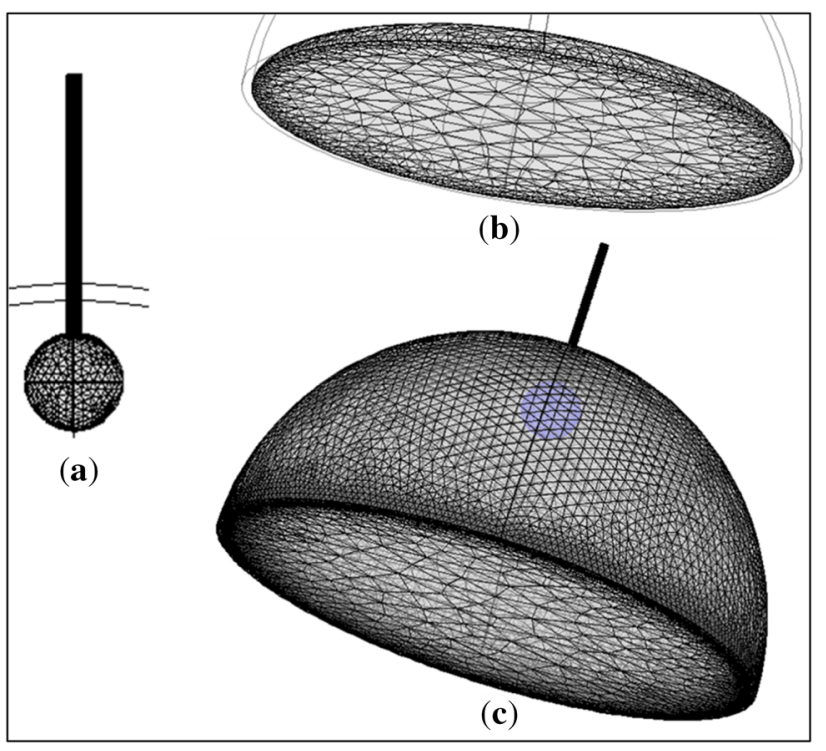

Figure 3. Meshing details around different domains: (a) electrode and tumor, (b) muscle and (c) entire breast model.

options on the basis of number of mesh elements (in ascending order), viz., extremely coarse, extra coarse, coarser, coarse, normal, fine, finer, extra fine and extremely fine. The grid independence study has been conducted to determine the optimal number of mesh elements for reducing computational cost and to ascertain that simulation results are independent of number of mesh elements. Table 2 presents the result of the grid independence study in terms of ablation volume attained after 20 min of RFA procedure without any convective cooling for different meshing options of COMSOL's built in mesh generator. The present study considers multi-zonal grids with an extra fine mesh at the electrode and tumor domains (due to the prevalence of high electrical and thermal gradients), finer mesh at gland and fat domains, and normal mesh at muscle domain that is away from the electrode (see figure 3 ). The final optimal mesh consists of 3,55,064 elements for which the maximum error is less than $0.2 \%$ as compared to $e x$ tremely finer meshing option.

The pre-specified relative tolerance for the electric field and heat transfer interface has been set to 0.0001 . The multifrontal massively parallel sparse (MUMPS) direct linear solver has been used for solving the linear system of equations of electric field, while iterative conjugate

Table 2. Results of grid independence study.

\begin{tabular}{|c|c|c|c|}
\hline Mesh type & Number of mesh elements & $\%$ change in ablation volume & $\%$ change in computation time \\
\hline Extremely coarse & 17,541 & - & - \\
\hline Normal & 51,152 & 2.69 & 199.08 \\
\hline Fine & 96,355 & 1.25 & 72.85 \\
\hline Finer & $2,93,493$ & 0.53 & 344.72 \\
\hline Extra fine & $10,05,642$ & 0.15 & 1456.28 \\
\hline
\end{tabular}


gradient method has been used for solving the temperature field. The implicit time-stepping method backward differentiation formulas (BDF) has been used to find the solution to the time-dependent problem and care has been taken to store the data at each step by assigning strict steps to the solvers. The Newton-Raphson algorithm has been used for iterations in both direct and iterative solvers. All numerical simulations have been performed on a Dell Precision Tower 7810 workstation with eight Core $3.1 \mathrm{GHz}$ Xeon processors and 64 GB RAM.

\section{Results and discussion}

The numerical model fidelity and integrity have been evaluated by comparing the computational results with the experimental results obtained by conducting the temperature-controlled RFA on the polyacrylamide based tissuemimicking phantom gel. A commercially available electrosurgical radiofrequency generator (RITA 1500X, AngioDynamics Inc., Latham, NY) and multi-tine RITA Starburst XL electrode have been used for the validation purpose, as reported in our previous studies [14, 26]. The validation of mathematical models of temperature-controlled RFA has been done considering both temperature measurement [14] and size of ablation volume approaches [26] on the cylindrical shaped homogeneous phantom gel that has been considered as the test case. Importantly, a good agreement has been obtained between the temperature distribution obtained from numerical and experimental studies at two locations, viz., $5 \mathrm{~mm}$ and $10 \mathrm{~mm}$ below the electrode tip. Additionally, the time to reach the target temperature has been found to be $3.17 \mathrm{~min}$ and $2.95 \pm$ $0.3 \mathrm{~min}$ from numerical and experimental studies, respectively [14]. Further, the ablation volume obtained from experimental and numerical studies during temperature-controlled RFA have been found to be $17.36 \pm 1.86 \mathrm{~cm}^{3}$ and $17.61 \mathrm{~cm}^{3}$, respectively [26]. Henceforth, after reaffirming the faith in computational simulations, the numerical study has been extended on the heterogeneous model of breast.

The temperature distribution from the outer surface of the breast along a line parallel to the electrode axis has been shown in figure 4 . The parallel line has been taken at a distance of $1.5 \mathrm{~mm}$ from the central electrode axis so as to avoid intersection with the electrode, as shown in figure 4(a). It is evident from figure 4(b) that without any convective cooling (i.e., when $h=0 \mathrm{~W} / \mathrm{m}^{2} \mathrm{~K}$ ) the temperature at the outer surface of breast is severely high after 20 minutes of temperature-controlled RFA procedure. Not only this, but the entire skin layer is subjected to temperature greater than $75^{\circ} \mathrm{C}$ post-RFA procedure, as can be seen in figure 4(b). The application of forced convective cooling at the outer skin surface of the breast drastically reduces the maximum temperature at the surface of the breast to less than $40^{\circ} \mathrm{C}$, as depicted in figure $4(\mathrm{~b})$. The drop in the

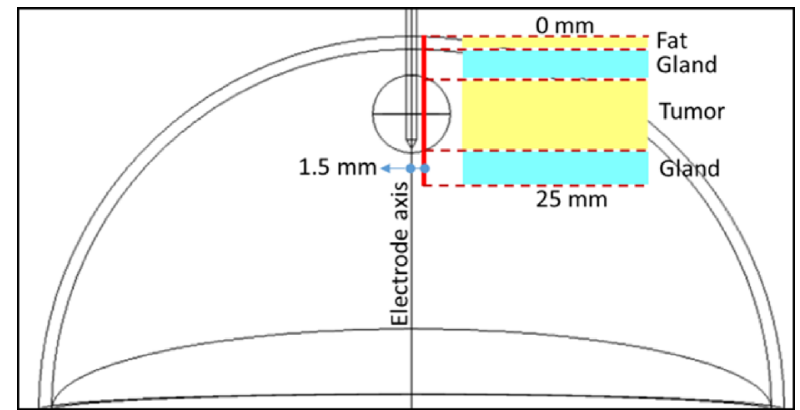

(a)

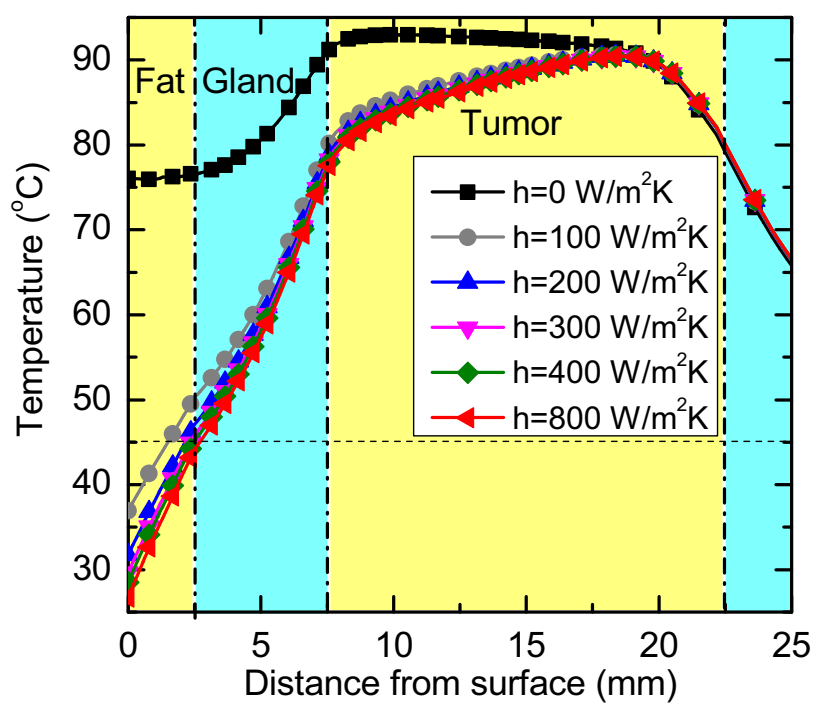

(b)

Figure 4. (a) Schematic diagram representing a line parallel to electrode axis across which temperature has been measured, and (b) temperature profiles as function of distance from skin surface after 20 minutes of RFA application.

maximum temperature at the outer surface of breast with application of forced convective cooling has been found to be $51.44 \%, 58.30 \%, 61.02 \%, 62.48 \%$ and $64.81 \%$ for the convective heat transfer coefficients of 100, 200, 300, 400 and $800 \mathrm{~W} / \mathrm{m}^{2} \mathrm{~K}$, respectively. It is noteworthy to mention that, very negligible variation in the drop of maximum temperature has been found beyond convective heat transfer coefficient of $800 \mathrm{~W} / \mathrm{m}^{2} \mathrm{~K}$.

The motive of the present numerical study is not only to decrease the surface temperature of breast but also to make sure that the entire skin layer is being preserved, i.e., the temperature at the fat-gland junction should be less than $45^{\circ} \mathrm{C}$, in order to avoid first degree burns. As depicted in figure 4(b) that, the temperature at fat-gland junction is lower than $45^{\circ} \mathrm{C}$ only for the case when convective heat transfer coefficient is $800 \mathrm{~W} / \mathrm{m}^{2} \mathrm{~K}$. Further, a marginal drop of $10^{\circ} \mathrm{C}$ has been reported at the tumor periphery close to the breast surface subjected to forced convection cooling during RFA application. However, this drop does not 


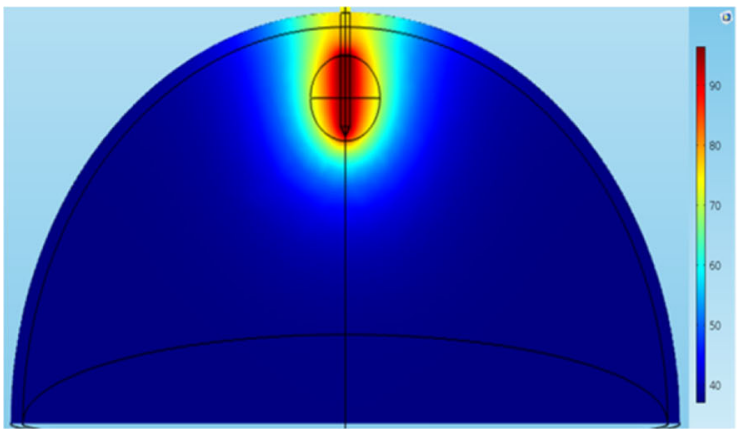

(a)

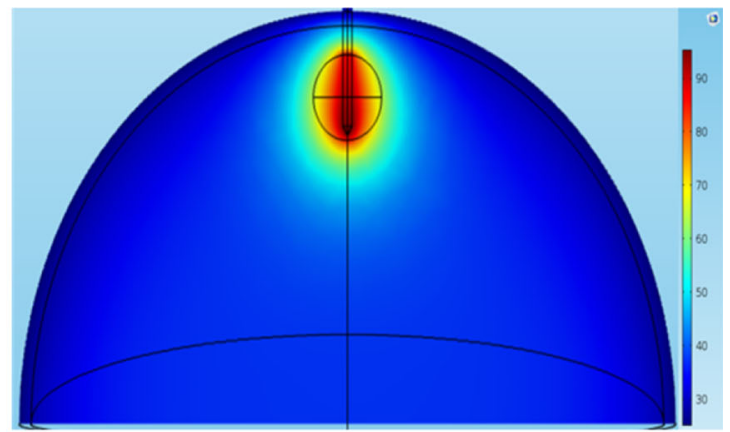

(b)

Figure 5. Temperature distribution along a plane parallel to electrode: (a) without and (b) with surface cooling.

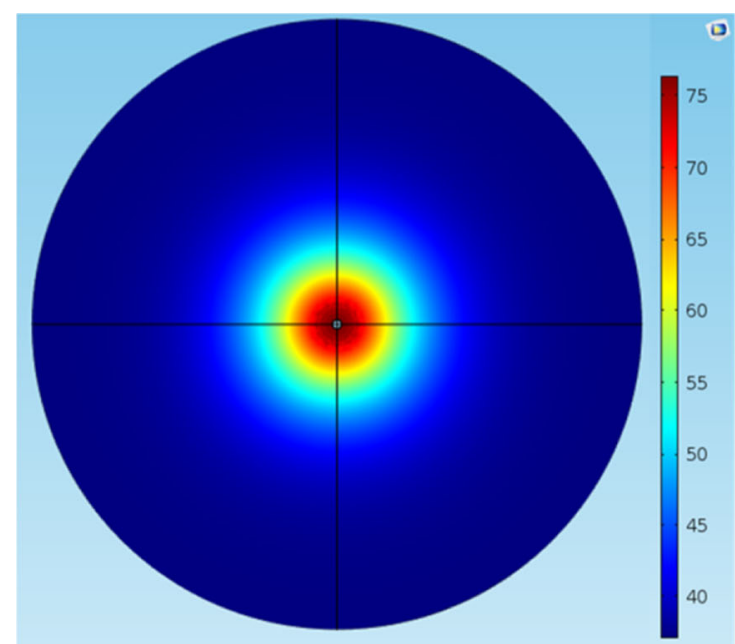

(a)

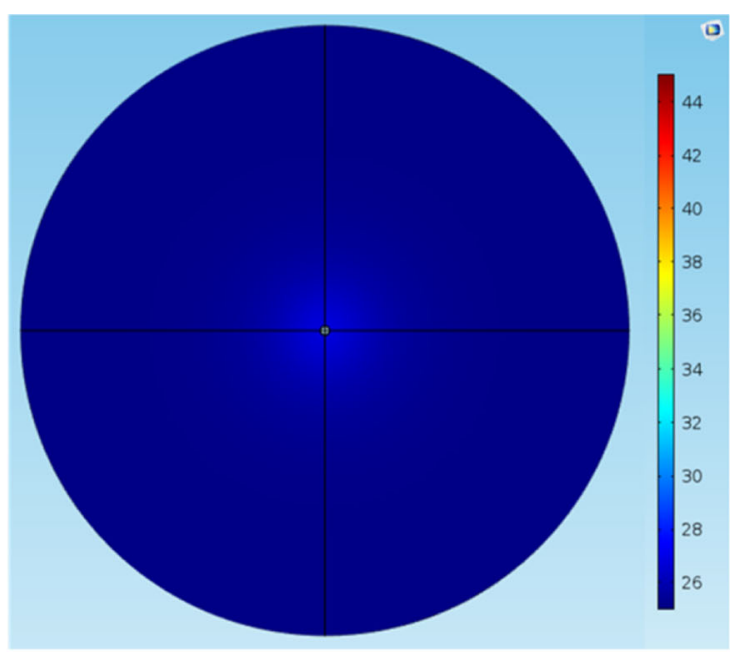

(b)

Figure 6. Temperature distribution at the skin surface of breast: (a) without and (b) with surface cooling.

hinders the process of tumor ablation, since the entire tumor is being subjected to a temperature greater than $75^{\circ} \mathrm{C}$ for all values of convective heat transfer coefficient. The only consequence of such drop could be either a rise in treatment time to attain complete tumor necrosis or rise in power supplied during RFA procedure.

Figure 5 shows the temperature distribution along a plane parallel to electrode surface subjected to two cases, viz., no convective cooling $\left(h=0 \mathrm{~W} / \mathrm{m}^{2} \mathrm{~K}\right)$ and with convective cooling $\left(\mathrm{h}=800 \mathrm{~W} / \mathrm{m}^{2} \mathrm{~K}\right)$, during temperaturecontrolled RFA of breast tumor. It can be seen from figure 5 that, there has been a subsequent reduction in the heating at the breast surface with the application of forced convective cooling during RFA procedure. Further, figure 6 depicts the temperature distribution at the outer periphery of breast from the top view of the breast model, with and without forced convective cooling. It can be clearly seen from figure 6 that, with application of forced convective cooling there is no heating at surface of breast. Hence, the simultaneous application of convective cooling along with
RFA could help in minimizing the skin burn problems in breast, specifically for tumor located close to the breast surface.

The evolution of tumor ablation volume for different values of convective heat transfer coefficients considered in the present study, has been illustrated in figure 7 . It can be seen from figure 7 that the time required for attaining complete tumor necrosis of $1.5 \mathrm{~cm}$ diameter tumor increases as the value of convective heat transfer coefficient increases during RFA. The treatment time required for complete tumor necrosis without any convective cooling has been found to be 11.67 minutes during temperaturecontrolled RFA. Further, with convective cooling, the time required for complete tumor necrosis increases to 15.33 , $16.33,17,17.33$ and 18 minutes for the convective heat transfer coefficients of 100, 200, 300, 400 and $800 \mathrm{~W} / \mathrm{m}^{2} \mathrm{~K}$, respectively. Such marginal rise in the treatment can be tolerated by patient in order to minimize skin burns and attain better cosmesis during RFA of breast tumor. Further, the variation of applied voltage with time for different 


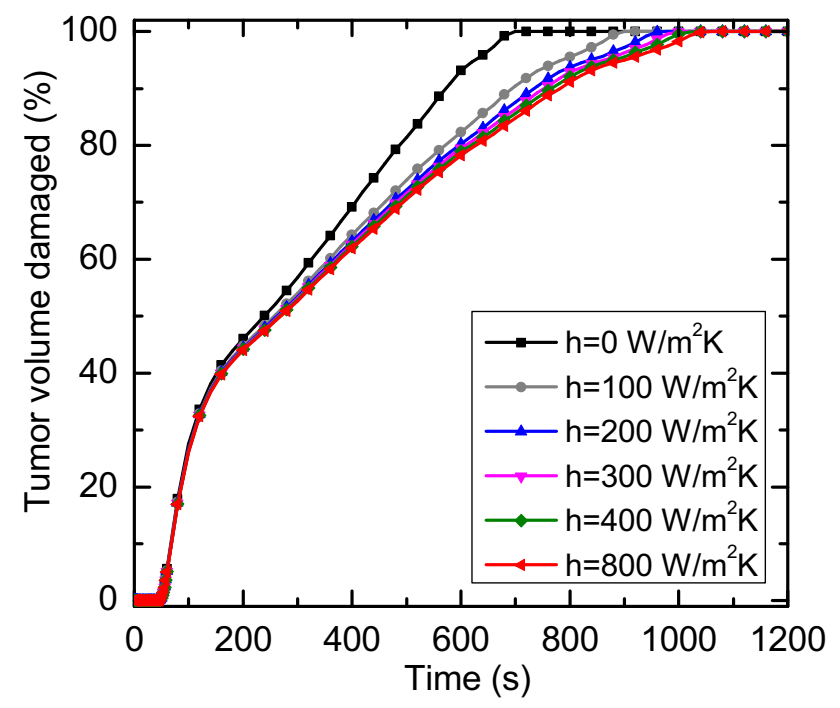

Figure 7. Variation of tumor volume damaged with time for different values of convective heat transfer coefficients.

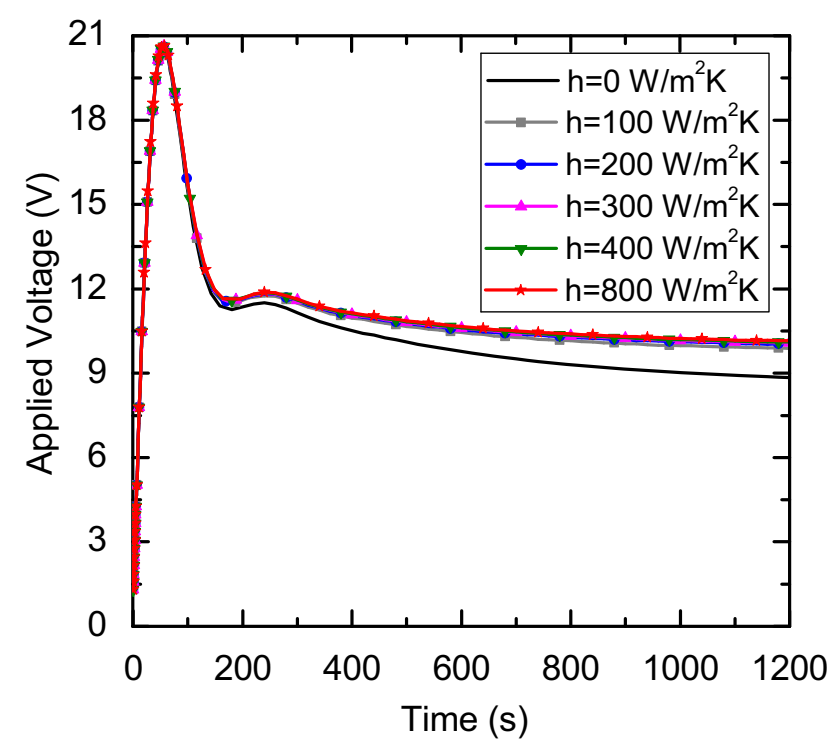

Figure 8. Variation of input voltage with time for different values of convective heat transfer coefficient.

values of convective heat transfer coefficient during temperature-controlled RFA has been shown in figure 8. It is evident from figure 8 that a negligible variation prevails among the different cases considered in the present study.

\section{Conclusion}

A numerical study has been conducted to address the most common problem of skin burns during RFA application in treating breast tumor. The efficacy of forced convective cooling in minimizing skin burns during RFA has been evaluated by conducting the thermo-electric analysis on the three-dimensional heterogeneous breast model. It has been found that, application of forced convective cooling during RFA results in a significant drop of maximum temperature at the outer periphery of breast as compared to the case of convective cooling being absent. The numerical study revealed that the application of forced convective cooling with RFA results in a marginal rise in the treatment time required for complete tumor necrosis from 11.67 minutes to maximum of 18 minutes. It has been further found that the convective cooling at the surface of breast has negligible effect on the input voltage requirement during RFA application. The present study suggests that simultaneous convective cooling along with RF heating could help in minimizing the skin burns in breast during RFA application of tumor located close to the breast surface.

\section{Acknowledgements}

Authors would like to thank Science and Engineering Research Board, Department of Science and Technology, Government of India, for providing the grant (Grant number SB/FTP/ETA-0135/2013) to pursue the present research work. Authors also would like to thank Indian Institute of Technology Ropar for providing essential infrastructure.

\section{References}

[1] Ferlay J, Soerjomataram I, Dikshit R, Eser S, Mathers C, Rebelo M, Parkin D M, Forman D and Bray F 2013 GLOBOCAN 2012 v1.0 Cancer Incidence and Mortality Worldwide: IARC. http://globocan.iarc.fr

[2] National Program of Cancer Registries 2014 http://ncrpindia. org/Annual_Reports.aspx

[3] Bajaj A K, Kon P S, Oberg K C and Miles D A 2004 Aesthetic outcomes in patients undergoing breast conservation therapy for the treatment of localized breast cancer. Plast. Reconstr. Surg. 114: 1442-1449

[4] Al-Ghazal S K, Blamey R W, Stewart J and Morgan A A 1999 The cosmetic outcome in early breast cancer treated with breast conservation. Eur. J. Surg. Oncol. 25: 566-570

[5] Nguyen T, Hattery E and Khatri V P 2014 Radiofrequency ablation and breast cancer: a review. Gland Surg. 3: 128-135

[6] Chu K F and Dupuy D E 2014 Thermal ablation of tumours: biological mechanisms and advances in therapy. Nat. Rev. Cancer 14: 199-208

[7] Miller M W and Ziskin M C 1989 Biological consequences of hyperthermia. Ultrasound Med. Biol. 15: 707-722

[8] Jeffrey S S, Birdwell R L, Ikeda D M, Daniel B L, Nowels K W, Dirbas F M and Griffey S M 1999 Radiofrequency ablation of breast cancer: first report of an emerging technology. Arch. Surg. 134: 1064-1068

[9] Oura S, Tamaki T, Hirai I, Yoshimasu T, Ohta F, Nakamura R and Okamura Y 2007 Radiofrequency ablation therapy in 
patients with breast cancers two centimeters or less in size. Breast Cancer 14: 48-54

[10] Wahab A A, Salim M I M, Ahamat M A, Manaf N A, Yunus J and Lai K W 2016 Thermal distribution analysis of three-dimensional tumor-embedded breast models with different breast density compositions. Med. Biol. Eng. Comput. 54: 1363-1373

[11] Singh R, Das K, Mishra S C, Okajima J and Maruyama S 2015 Minimizing tissue surface overheating using convective cooling during laser-induced thermal therapy: a numerical study. J. Therm. Sci. Eng. Appl. 8: 11002-6

[12] Anvari B, Milner T E and Tanenbaum B S 1998 A comparative study of human skin thermal response to sapphire contact and cryogen spray cooling. IEEE Trans. Biomed. Eng. 45: 934-941

[13] Singh S, Bhowmik A and Repaka R 2016 Thermal analysis of induced damage to the healthy cell during RFA of breast tumor. J. Therm. Biol. 58: 80-90

[14] Singh S and Repaka R 2017 Temperature-controlled radiofrequency ablation of different tissues using two-compartment models. Int. J. Hyperth. 33: 122-134

[15] Pennes H H 1998 Analysis of tissue and arterial blood temperatures in the resting human forearm. J. Appl. Physiol. 85: 5-34

[16] Zhang B, Moser M A, Zhang E M, Luo Y, Zhang H and Zhang W 2014 Study of the relationship between the target tissue necrosis volume and the target tissue size in liver tumours using two-compartment finite element RFA modelling. Int. J. Hyperth. 30: 593-602

[17] Schutt D J and Haemmerich D 2008 Effects of variation in perfusion rates and of perfusion models in computational models of radio frequency tumor ablation. Med. Phys. 35: 3462-3470

[18] Singh S and Repaka R 2015 Pre-clinical modelling and simulation of hepatic radiofrequency ablation. In: Proc.
COMSOL Conference 2015 (Pune, India 29-30 October 2015)

[19] Abraham J P and Sparrow E M 2007 A thermal-ablation bioheat model including liquid-to-vapor phase change, pressure-and necrosis-dependent perfusion and moisture-dependent properties. Int. J. Heat Mass Transf. 50: 2537-2544

[20] Singh S, Bhowmik A and Repaka R 2015 Radiofrequency ablation of malignant breast tumor: A numerical study. In: Proc. 23rd National Heat and Mass Transfer Conference and 1st International ISHMT-ASTFE Heat and Mass Transfer Conference (Thiruvananthapuram, India, 17-20 December 2015), Paper no. IHMTC2015-538

[21] Henriques F C 1947 Studies of thermal injury V: the predictability and significance of thermally induced rate processes leading to irreversible epidermal injury. Arch. Pathol. 43: 489-502

[22] Singh S and Repaka R 2017 Effect of different breast density compositions on thermal damage of breast tumor during radiofrequency ablation. Appl. Therm. Eng. 125: 443-451

[23] Haemmerich D and Webster J G 2005 Automatic control of finite element models for temperature-controlled radiofrequency ablation. Biomed. Eng. Online 4

[24] Jamil M and Ng E Y K 2015 Quantification of the effect of electrical and thermal parameters on radiofrequency ablation for concentric tumour model of different sizes. J. Therm. Biol. 51: 23-32

[25] Singh S and Repaka R 2016 Effects of target temperature on ablation volume during temperature-controlled RFA of breast tumor. In: Proc. COMSOL Conference 2016 (Bangalore, India 20-21 October 2016)

[26] Singh S and Repaka R 2018 Parametric sensitivity analysis of critical factors affecting the thermal damage during RFA of breast tumor. Int. J. Therm. Sci. 124: 366-374 